\title{
Opinion
}

\section{ObamaCare: One More in a Long Line of Bad Ideas}

James M. Sprouse, MS

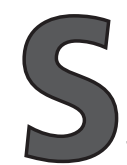

ince 1965, with the establishment of the Medicare and Medicaid programs, the United States has been involved in what has now become a 45-year journey to "reform" the health care system. That is not to say that U.S. health care had not, like any industry, undergone many substantive changes in the last century, but rather that, since 1965 there has been a growing recognition, and finally, acceptance, that the health care system, as a whole, was somehow seriously flawed (1-5).

Title XVIII and XIX (Medicare \& Medicaid) were intended to eliminate cost as a barrier to health care for the elderly and the poor (6). Then, in the 1970s, various states tried rate-setting as a means of cost control. President Richard Nixon tried price controls in an effort to curb what was seen as runaway health care costs (7). Health planning, via the 1974 National Health Planning and Resources Development Act (PL 93-641), aimed to control costs. Utilization Review and the Professional Standards Review Organizations were cost control mechanisms that extended into the 1980 s (8). In the mid 1980s up to today, Medicare reimbursement practices have been arbitrarily limited by the Prospective Payment System (PPS) with its Diagnosis Related Groups (6), and its successors. The Resource Based Relative Value System was implemented to reduce Medicare payments to physicians similar to the way PPS reduced hospital reimbursement (9). Even the Clintons' Health Care Reform Plan was primarily an attempt to hold down costs. Again and again over the last 45 years, cost control has been a major agenda for the U.S. government in its dealings with the nation's health care system.

As a response to all of these cost control efforts, health care providers have reorganized, down-sized, corporatized, and ultimately realized little reduction in cost.

Managed Care organizations, which combine health care providers with a financing mechanism, such as Health Maintenance Organizations, became increasingly popular (6). Vertical and horizontal integration, mergers, acquisitions, and multi-institutional health systems all continue to be tried as health care providers fight to hold down costs.

Obviously, someone decided that high cost was the "flaw" in the U.S. health care system. Ever since Congress realized that Medicare's original \$3 billion annual budget was underestimated by tens of billions of dollars, the cost of health care has been the unwavering focus of every stakeholder in the U.S. health care system. President Obama's health care reform package is again, ultimately, the most elaborate strategy since 1965 to overhaul the provision and financing of health care in this country. Once again, this "reform" is being promoted as the best way to hold down the cost of a health care system to which every U.S. citizen is supposedly guaranteed access.

For four decades, those in power have been saying that U.S. health care costs too much. "Health care providers are inefficient... Doctors and hospitals make too much money... Drug companies are ripping us off..." are all common complaints which grew out of the concept that health care costs were out of control - that excessive cost was the issue.

While there is some truth to all of those statements, it is equally true those health care providers,

From: Pain Management Center of Paducah, Paducah, KY Sprouse is Administrator of the Pain Management Center of Paducah and the Ambulatory Surgery Center LLC, Paducah, KY. E-mail: james@thepainmd.com

Disclaimer: There was no external funding in the preparation of this manuscript. Conflict of interest: None. 
in general, are no more inefficient than any other industry in this country. Individual physicians may earn 3 to 5 times the average U.S. personal income, but so do lawyers, business executives, politicians, and a multitude of other professions. Furthermore, the majority of dollars spent on actual health care flows to hospitals (10), in which the average profit has been less than $10 \%$, and as low as $2 \%$ per year since 1975 (11). Longterm care facilities typically show an even smaller margin. There are very few industries in this country that could long survive with such small operating margins. Finally, pharmaceutical companies can invest as much as $\$ 150$ million in researching a single new drug, and then wait anywhere from 3 to 10 years for Food \& Drug Administration approval to market it (12). Who is to say how quickly these companies should be permitted to recoup their investment, much less profit on it? Perhaps cost is not the problem.

Perhaps the true issue that has been the focus, however appropriately, and simply miscast as "excessive cost," is that the U.S. is "spending too much" on health care.

The two terms are NOT synonymous. The first implies a problem with the way health care is provided and priced, hence the 45-year focus on health care providers. The second implies that, regardless of whether the actual cost is appropriate, the nation simply does not have enough money in its pockets to pay that cost. Furthermore, and probably equally true, the nation chooses to spend what it does have on other things. For example, suppose a child was given one dollar and told that it was permissible to spend the money to buy lunch. If the child went to the candy store and purchased twenty pieces of bubble gum, the parents might admonish the child for not spending the money wisely. The parents would probably not, however, castigate the storeowner because the bubble gum cost too much.

Like that child who did not know enough or care to spend the dollar wisely, widely available health insurance and a belief that health care is the "right" of every citizen has seemingly led the U.S. population, on an individual basis, to be singularly unprepared to make prudent health care purchases. How has the widespread availability of health insurance and the "right" to health care contributed to runaway health care expenditures?

Standard insurance operates under the assumption that most people will want to avoid the losses covered by their insurance. Most individuals would not build a fire on their living room floor, so as to reduce the risk of burning their house down. They don't, even though they may love campfires and in fact, have insurance to cover losses from fire damage. Such concern is not always the case in the health insurance arena. For millions of people, the potential life-threatening risk of lung cancer is not perceived as sufficient enough for them to quit smoking. Similarly, although most health insurance policies do require deductible and co-pay portions, the "losses" are not of sufficient magnitude to result in behavior change. In other words, a \$25 copay requirement on a doctor's office visit is typically not a deterrent sufficient enough for most people to forego the visit or even to avoid the activity that may result in the need for the visit in the first place. How do you "insure" risk that the majority of the population chooses to ignore?

This question leads to a discussion of the way that health insurance is different, and ultimately why such insurance results in excessive expenditures. The "moral hazard" of health insurance refers to the temptation to over-utilize it, simply because it is available (13). Physicians, hospitals, and other health care providers conspire (intentionally or not) to maximize use of health insurance. It is far too common an occurrence for a physician and a patient to jointly make their decision on which diagnostic tests to order based on which tests are covered by insurance in addition to clinical justification. Similarly, it is not uncommon for patients to be admitted to a hospital for treatment which could be provided on a less costly outpatient basis simply because the insurance coverage is better for inpatient services. Although this practice is less common in light of the growing influence of managed care programs, it still occurs regularly. In other words, the very existence of health insurance can stimulate demand. In fact, the use of health insurance can result in significant unnecessary expenditures as patient after patient (in conjunction with their provider) says, "If my insurance covers it, I'll take it." The bottom line is this - health insurance is not really "insurance" in the U.S.; it's how we buy health care. In this scenario, the ultimate beneficiary, the patient, is insulated from the actual cost of that purchase.

Finally, the availability of health insurance has not been the only contributor to excess expenditures on health care. An additional factor has been the result of a general consensus that, "...some minimum level of health care is a right..." of every citizen in this country (14). Unfortunately, the rapid and continuing development of new technology, treatment regimens, and pharmaceutical agents has made the definition of 
"...some minimum level..." virtually impossible. Other nations have significantly limited the availability of various advanced diagnostic and treatment regimens. Early attempts to do so in this country, even for small segments of the population have been met with tremendous resistance. One example is the Oregon experience, an attempt to prioritize a list of health services from the most to the least important based on effectiveness, cost, and quality of life - which President Bush and the Department of Health and Human Services rejected. "Rationing," (i.e., limiting availability of certain services to certain population segments) is still highly controversial, albeit practiced widely $(14,15)$. Therefore, irrespective of insurance availability or other forms of financing, the U.S. health care system tends to try to provide not the "minimum" but the "best" possible care to everyone. Again, prudent shopping becomes unnecessary for the typical health care consumer.

Throughout the system, therefore, it would seem that health care dollars are not spent wisely because expenditures are not the overriding concern. Perhaps health care in this country does not "cost" too much. Perhaps the true issue, one that the U.S. government has recognized since 1968, is that "costs" are not too high - expenditures are.

Many experts would agree that health care expenditures in the U.S. are too high, as this country spends a greater percentage of its gross national product on health than do most other industrialized nations (16). However, even those who propose switching the U.S. system to some form of the various socialized systems prevalent in other nations still tend to focus on reducing "costs" instead of "expenditures." This 45-year shift in focus is easier to understand when considering the alternative facing U.S. political leaders. As previously mentioned, the government knew by 1968 that its original spending estimates related to Medicare were seriously understated and that the program was proving to be prohibitively expensive. However, rather than ask the voting public for significantly more funding, or to accept reduced services, both of which were perceived as political suicide, the government chose to "decide" that health care cost too much. In that way, concentration could be focused on health care providers. No politician would ever have to tell a constituent that they could not have a "needed" health service. By saying health care providers cost too much, and therefore should be willing to accept reductions in the amount they would be reimbursed for their services, legislators left the odious task of saying, "No!" to a patient to providers. For 45 years that philosophy has prevailed. It seems likely that few politicians truly believe "costs" are too high. It is just that such a concept is more politically palatable. President Obama's health care plan, as did President Clinton's, follows that exact philosophy.

Furthermore, in almost every socialized health system in the industrialized world (Japan, Canada, England, Germany, the Scandinavian countries, etc.), where much (although certainly not all) of the bureaucratic waste, defensive medicine, and excess insurance profits that plague U.S. health care have been at least partially dealt with, the health care systems are in serious financial trouble. Why are even these socialized systems running out of money? Although there are issues specific to individual nations, one overriding concern is prevalent. Just as in the U.S., modern health care technology, and its continuing advancements, have placed all modern health care systems in the same predicament: being able to provide far more health care services than can ever be paid for (13).

If the U.S. is indeed spending too much on a product (health care) which it seemingly has an unlimited demand for, how will health care expenditures be controlled? Is it fair, or even morally acceptable in this country for the government to say, "You cannot have that magnetic resonance image (MRI) exam because it is too expensive"?

Pennsylvania's Senator Arlen Specter would give a heartfelt NO, since it was only a last resort MRI scan that revealed the brain tumor which would have killed him (17). What will happen when treatment really gets expensive? When technology begins to grow organs for replacement (likely within the next 20 years), will the $\$ 100$ million price tag on equipment and the $\$ 100,000$ per case expenditures mean the U.S. will have to continue its present rationing system for organ transplants? To date, the public has accepted the fact that there are simply not enough organs harvested from dying individuals to meet the demand. What will happen when the answer is, "Yes, Mr. Smith we do have a heart for you. However, your insurance company can only afford 4 transplants per year, so we'll just add your name to our waiting list. Don't worry though, you're only number 23" ? Nor will any government-sponsored, (or mandated as President Obama desires) health care program have the kind of capital it will take to pay for all the Mr. Smiths out there (which is likely to be almost everyone at some point in their lives). Somehow it seems unlikely 
that Mr. Smith will accept that line of reasoning, especially since someone else is making a purely economic decision, which will likely cost him his life.

So what is the way to control health care expenditures? Economists would say that it is mandatory to reduce demand. Since the actual consumer of health care services (i.e., the person who directly receives the diagnostic test and/or treatment) is, for $85 \%$ of the U.S. population, not the direct purchaser of those services, there is little perceived need or incentive for the consumer to make prudent decisions concerning utilization of those services. The direct purchaser (i.e., insurance and/or other financing organizations of various types) also evidences a limited ability to make prudent purchase decisions because of an inability to determine an acceptable level of service on an individual basis. Therefore, health care utilization, and thus expenditures, continue to escalate as the supply (new technology, etc.) of services increases. There are few, if any, typical open market forces reducing or limiting demand.

What would happen if health and health care became more of an individual responsibility? In this country, it is accepted that hard work and dedication can determine the quality and amount of food, shelter, and clothing individuals can afford. Could these same qualities determine the quality and amount of health care? Just as the decision to buy a more expensive home may reduce the quality of auto driven, what would happen if the decision to undergo a lung transplant, especially if one is a smoker, reduces the quality of home one could afford? It seems unlikely that U.S. citizens will ever give up their "right" to decide what risks they want to take with their own lives. Since, in that context, many health care decisions may ultimately have an effect on whether they live or die, the U.S. may never be able to decide, as a society, what would be a "minimum acceptable level" in health care. For instance, currently many health insurance carriers provide some level of reimbursement for various diagnostic routines in relation to an actuarially determined risk based on age, gender, and other demographic variables. However, it is obvious in such a scenario that some individuals, like Senator Specter, would not receive a diagnostic procedure that might have benefited them. So should all citizens receive an MRI or perhaps a complete physical examination every year? Obviously, the answer is no. The country and its insurance carriers could not afford that. Therefore, insurance companies, as with the Mr. Smith example above, will be forced to make decisions based on financial factors alone, with little or no credence given to potential outcomes. The already growing number of lawsuits filed by bereaved families against carriers who refused coverage for a particular health service is testimony to the dangers inherent in that scenario.

Shifting health care purchase decisions to the actual consumer could alleviate the liability problem mentioned above. An obvious way to facilitate that shift is to remove, or at least significantly reduce, the insurance role, and let individuals pay for those health services they desire directly out of their own pocket. When health care becomes more of a true "consumer good," it may be reasonable to expect that typical market forces will indeed affect, and hopefully reduce demand. It would certainly seem logical to assume that very expensive diagnostic and/or treatment regimens would exceed the ability or willingness of many people to pay, thereby reducing demand. An individual may well decide to forego the cost of an additional, expensive diagnostic procedure and take the chance that the diagnosis based on a simple $\mathrm{x}$-ray is correct. Senator Specter might still order that MRI scan, but he would do so knowing that he was spending this year's vacation money. In short, letting the basic laws of supply and demand take effect may well do more to reduce health care expenditures than any arbitrary controls which society could impose. Then health insurance could be used as truly "insurance" against catastrophic loss.

The president's health care plan simply tries to shift even more of the burden of paying for health care to employers and indirectly, to those who currently don't buy health insurance (because they don't perceive the need or can't afford it) by mandating the purchase of health insurance for everyone. It will not solve the problem. It will not reduce demand. It will, however, continue prohibitive increases in health care expenditures. Most politicians, and the president, talk about the "hard choices" that need to be made. Unfortunately, they seem to believe the American public is either incapable or unwilling to make them, so the government must make the choices for the people. But the "correct" choices are politically unpalatable, so they end up just prolonging the status quo in varying guises. Perhaps it is time to trust that Americans, in general, are mature, responsible adults who are perfectly capable of making their own "hard choices" on what health care they are willing to pay for. 


\section{References}

1. Manchikanti L, Caraway DL, Parr AT, Fellows B, Hirsch, JA. Patient Protection and Affordable Care Act of 2010: Reforming the health care reform for the new decade. Pain Physician 2011; 14; E35-E67.

2. Public Law No: 111-148: H.R. 3590. Patient Protection and Affordable Care Act. March 23, 2010.

3. Manchikanti L, Singh V, Caraway DL, Benyamin RM, Hirsch JA. Medicare Physician Payment Systems: Impact of 2011 schedule on interventional pain management. Pain Physician 2011; 14; E5E33.

4. Manchikanti L, Hirsch JA. Obama health care for all Americans: Practical implications. Pain Physician 2009; 12:289304.

5. Bredesen P. Fresh Medicine: How to Fix Reform and Build a Sustainable Health Care System. First Edition. Atlantic
Monthly Press, New York, 2010.

6. Williams SJ, Torrens PR. Introduction to Health Services. 5th Edition. Delmar Publishers, Albany, NY, 1999.

7. Thomas, K. Nixon's price controls on health care won't work. Houston Post. May 18, 1994:C:1

8. Blum JD, Gertman PM, Rabinow J. PSROs \& the Law. Aspen, Germantown, MD, 1977.

9. Grimaldi, PL. RBRVS: How new physician schedule will work. Healthc Financ Manage 1991; 45:58-75.

10. Cleverly WO. Essentials of Health Care Finance. 4th Edition. Aspen, Gaithersburg, MD, 1997.

11. Griffith JR. The Well-Managed Health Care Organization. AUPHA Press, Ann Arbor, MI, 1995.

12. DiMasi JA, Hansen RW, Grabowski HG, Lasagna $L$. The cost of innovation in the pharmaceutical industry. J Health Econ
1991; 10:107-142.

13. Smith S, Newhouse JP, Freeland MS. Income, insurance, and technology: Why does health spending outpace economic growth? Health Aff 2009; 28:12761284.

14. Reinhardt UE. On the economics and ethics of rationing health care. Journal of Health Economics 1992; 5:10-16.

15. Borger C, Smith S, Truffer C, Keehan S, Sisko A, Poisal J, Clemens MK. Health Spending projections through 2015: Changes on the horizon. Health Aff 2006. http://content.healthaffairs. org/content/25/2/w61.long.

16. Anderson GF, Reinhardt UE, Hussey PS, Petrosyan V. It's the prices stupid: Why the United States is so different from other countries. Health Aff 2003; 22:89-105.

17. Johnson J, Thompson D. Health dissent. Time. October 11, 1993. 
